\title{
Agricultura familiar, extrativismo e sustentabilidade: o caso dos "samambaieiros" do litoral norte do Rio Grande do Sul ${ }^{1}$
}

\author{
Rafael Perez Ribas* \\ Christiane Marques Severo** \\ Lovois de Andrade Miguel***
}

Resumo: O artigo apresenta os resultados de uma pesquisa sobre a sustentabilidade dos agricultores extrativistas da região da Encosta Atlântica do Rio Grande do Sul. O extrativismo em questão é de uma espécie conhecida popularmente como samambaia-preta [Rumohra adiantiformis (G.Forest.) Ching]. Estima-se que 3 mil famílias da região têm nesta atividade, não-regulamentada por lei, sua principal fonte de renda. $\mathrm{O}$ grau de sustentabilidade dos agricultores foi estimado através da adoção de informações relativas às dimensões ambiental, social e econômica e aos critérios de produtividade, estabilidade, equidade, resiliência e autonomia. A análise focou-se na comparação entre os Índices Relativos das Dimensões (IRD), dos Critérios (IRC) e de Sustentabilidade (IRS) de cada tipo de sistema de produção. Os resultados apontaram para a existência de 4 tipos de sistemas de produção, sendo 3 deles abrangidos nessa pesquisa. Os sistemas de produção dos tipos 1 e 2 se caracterizam pela baixa disponibilidade de meios de produção e por uma grande dependência de rendas não-agrícolas e do extrativismo. $\mathrm{O}$ * Mestre em Economia pelo Centro de Desenvolvimento e Planejamento Regional (Cedeplar) da UFMG. Pesquisador do Cedeplar/UFMG. rpribas@cedeplar.ufmg.br

** Economista pela UFRGS. Mestranda do Programa de Pós-Graduação em Desenvolvimento Rural (PGDR) da UFRGS.

*** Doutor em Agricultura Comparada e Desenvolvimento Agrícola pelo INA-PG, França. Professor do Departamento de Ciências Econômicas e do Programa de Pós-Graduação em Desenvolvimento Rural (PGDR) da UFRGS. lovois@ufrs.br

${ }^{1}$ Os autores agradecem os comentários e sugestões de dois pareceristas anônimos.

Eventuais imperfeições remanescentes são de inteira responsabilidade dos autores. 
sistema de produção do tipo 3 é caracterizado pela prática de agricultura de subsistência e de atividades agrícolas de cunho comercial, sem depender muito da prática extrativista. Os indicadores de sustentabilidade apontaram que o sistema de produção do tipo 3 se mostrou o mais sustentável, seguido pelo tipo 2 e, por último, pelo tipo 1 .

Palavras-chave: sustentabilidade, sistemas de produção, Samambaiapreta, Mata Atlântica.

\section{Classificação JEL: O13, O18, Q01, Q12.}

Abstract: This article reports the results of a research about the sustainability of extractive farmers in the Atlantic slopes of Rio Grande do Sul. The extractive economy at issue is related to a species usually known as leather fern (Rumohra adiantiformis (G.Forest.) Ching). It is estimated that 3,000 families in the region perform this non-regulated activity, which is their only source of income. The sustainability degree of farmers was calculated from information related to environmental, social and economic dimensions, and to productivity, stability, equity, resilience, and autonomy criteria. The analysis focused on the comparison among the Indexes Related to Dimension (IRD), Criteria (IRC) and Sustainability (IRS) of each kind of production system. The results pointed to the existence of four kinds of production systems, and three of them were included in this research. The sustainability indexes showed that the production system type 3 was the most sustainable, followed by type 2 and, finally, type 1.

Key words: sustainability, production systems, Leather Fern, Atlantic Forest

JEL Classification: O13, O18, Q01, Q12.

\section{Introdução}

A Mata Atlântica, com vários ecossistemas associados, destaca-se por ser uma das duas florestas brasileiras de maior biodiversidade. Alguns dos fatores responsáveis por isso foram as intensas transformações 
que sofreu durante o período quaternário, caracterizado por fortes mudanças climáticas (KLEIN, 1975). Atualmente, ela é apontada como uma das duas florestas tropicais mais ameaçadas de extinção, com menos de $5 \%$ da cobertura original, sendo os remanescentes florestais pequenos e fragmentados (CONSÓRCIO MATA ATLÂNTICA \& UNICAMP, 1992).

De uma maneira geral, a região da Encosta Atlântica do Estado do Rio Grande do Sul, considerada como o limite austral da Floresta Ombrófila Densa (Mata Atlântica sensu stricto) no Brasil, tem sido submetida a um intenso processo de coleta de folhagens. Trata-se de uma atividade extrativista, que envolve uma parcela considerável da população local, seja através da coleta, do arrendamento de terras para esta atividade, ou da venda a grandes centros de consumo.

Por "samambaieiros”, entende-se aquele agricultor extrativista da espécie pteridófita Rumohra adiantiformis (G.Forest.) Ching (Dryopteridaceae - Pteridophyta), conhecida popularmente como samambaia-preta. Essa folhagem possui uma distribuição geográfica bastante ampla, com particular abundância nas áreas de domínio da Mata Atlântica (RIBAS \& MIGUEL, 2004). A utilização econômica dessa folhagem ocorre basicamente em arranjos ornamentais, como buquês e coroas fúnebres, e decorações, devido a sua resistência após a coleta.

Na Encosta Atlântica Gaúcha, a extração direta de folhagens é uma atividade, tanto no que tange aos aspectos econômicos como sociais, de relevante importância para alguns municípios. Embora não existam estudos precisos, estima-se que em Maquiné, Caraá, Itati, Terra de Areia, Santo Antônio da Patrulha, Morrinhos do Sul e Osório em torno de 3 mil famílias tenham na prática da extração dessas folhas sua principal fonte de renda, quando não única (RIBAS et al., 2002). Segundo estudo realizado no município de Maquiné (GERHARDT et al., 2000), parte considerável dessas famílias vivem nas encostas, geralmente nos fundos de vale, em pequenos lotes de terra, não apropriados a cultivos anuais.

Como já mencionada por Ribas e Miguel (2004), a coleta da folhagem intensificou-se a partir da década de 1970, envolvendo famílias inviabilizadas de cultivarem suas áreas agrícolas, seja pelas restrições da legislação ambiental ${ }^{2}$ ou pela disponibilidade restrita de áreas de

\footnotetext{
${ }^{2}$ Decreto 750 de 10/02/1993.
} 
cultivo. Apesar de proporcionar medidas que assegurem a preservação ambiental, a legislação impede que pequenos agricultores familiares possam produzir e assegurar a sua reprodução social no meio rural desta região. De fato, a atividade extrativista da folhagem, também proibida por lei, apesar de cada vez menos rentável economicamente aos agricultores, é uma das poucas alternativas restantes.

Apesar do diagnóstico geral da região apontar para uma situação de empobrecimento rural (ANAMA, PGDR-UFRGS, RS-RURAL, 2003), pouco se conhece sobre a sustentabilidade (econômica, social e ambiental) das unidades de produção agrícolas baseadas na atividade extrativa da pteridófita. Na busca pela elaboração de fundamentos técnico-científicos que possam subsidiar o licenciamento desta atividade extrativista e a formulação de políticas públicas adequadas, este artigo é uma continuidade do trabalho de Ribas e Miguel (2004). Este último objetivava estudar apenas os aspectos macro de comercialização do produto de extração, enquanto este novo artigo está centrado em questões micro do sistema de produção extrativista.

O objetivo do trabalho é determinar os principais sistemas de produção implementados pelos agricultores familiares "samambaieiros", assim como avaliar a sustentabilidade de cada sistema a partir das dimensões econômicas, sociais e ambientais. A região de estudo compreende os municípios de Maquiné, Caraá e Osório, “pólos” extrativistas dentro da Encosta Atlântica do RS.

O artigo está estruturado em três partes distintas: delineamento da metodologia utilizada para coleta das informações, cálculo dos indicadores e análise dos mesmos; apresentação da tipologia dos sistemas de produção identificados e suas relações com os índices de sustentabilidade; e, por fim, uma reflexão sobre a contribuição desta pesquisa com vistas à intervenção pública e a futuros estudos.

\section{Metodologia}

Sustentabilidade refere-se ao uso dos recursos biofísicos, econômicos e sociais, segundo sua capacidade em um espaço geográfico, para obter bens e serviços diretos e indiretos da agricultura e dos recursos naturais para satisfazer as necessidades das gerações futuras 
e presentes. O valor presente dos bens e serviços deve representar mais que o valor das externalidades e dos insumos incorporados, melhorando ou pelo menos mantendo de forma indefinida a produtividade do ambiente biofísico e social. Além disso, o valor presente deve estar eqüitativamente distribuído entre os participantes do processo (EHLERS, 1996).

Com vistas a este conceito, a metodologia, baseada nos trabalhos de Moura (2002), Lopes (2001) e Ferreira (2001), consiste em uma avaliação da sustentabilidade de sistemas de produção implementados por agricultores e produtores rurais a partir das dimensões: ambiental, social e econômica. Na qual, cada dimensão é delimitada a partir de cinco critérios:

(1) produtividade - avalia a eficiência do uso dos recursos e o rendimento do trabalho;

(2) estabilidade - a capacidade do ecossistema de absorver perturbações e permanecer inalterado;

(3) equidade - forma de distribuição dos recursos no ecossistema;

(4) resiliência - capacidade de um ecossistema em manter a produtividade diante de alterações ou agressões externas; e

(5) autonomia - grau de controle e capacidade de administrar o funcionamento dos agroecossistemas.

Um fator a ser considerado na metodologia a seguir, que se distingue de outros trabalhos na área (MOURA, 2002; LOPES, 2001), é que esta se propõe a avaliar sustentabilidade não só de forma relativa, comparando as informações dentro de um espaço geográfico limitado, mas também de forma absoluta, apontando para a condição geral deste espaço. Os métodos anteriores eram baseados em medidas derivadas da distribuição de alguns indicadores entre diferentes sistemas de produção de determinada região, apontando qual sistema é relativamente mais ou menos sustentável. O método proposto a seguir, baseado em medidas de desvios absolutos, auxilia também na reflexão sobre a sustentabilidade dos sistemas com um todo, não se limitando a avaliar, por exemplo, o mais sustentável dentre os de baixa sustentabilidade, ou o menos sustentável em um grupo de elevada sustentabilidade. 


\subsection{Coleta de informações}

Através de um questionário semi-estruturado, dirigido, ou seja, nãoaleatório, foram realizadas, no período compreendido entre janeiro a março de 2003, 33 entrevistas junto a agricultores familiares extrativistas de três municípios (Maquiné, Osório e Caraá) da região da Encosta Atlântica do Litoral Norte do Rio Grande do Sul.

Com os critérios acima descritos, formataram-se uma série de indicadores englobando as dimensões Ambiental, Social e Econômica. Estes indicadores foram elaborados a partir de informações qualitativas e quantitativas contidas nas entrevistas. Nos Quadros 1 e 2, são apresentadas, respectivamente, a classificação dos indicadores utilizados, segundo a dimensão e o critério em questão, e a definição de cada indicador.

Quadro 1. Classificação dos indicadores empregados para a avaliação dos critérios e das dimensões de sustentabilidade.

\section{DIMENSÃO}

Ambiental

Social

Econômica

\begin{tabular}{ccccccc}
\hline Produtividade & \multicolumn{2}{c}{ VA/AAA } & VA/UTHf & & VA/KI \\
\cline { 1 - 3 } \cline { 6 - 6 } Estabilidade & BAIX/SPT & FLOR/SPT & FUT & IDP & $1-($ PBext/PBT) \\
\hline Equidade & AAA/UTH & NEquip & BENS & & NRS \\
\hline Resiliência & MNJ & IUS & ESC & RNA & CRED \\
\hline Autonomia & SPT/ST & 1-(CI/PBT) & PART & 1-(DT/PBT) \\
\hline
\end{tabular}

Fonte: elaboração própria.

Cabe salientar que a definição dos indicadores foi pautada sobre a limitação das informações coletadas nas entrevistas, mais voltadas a questões econômicas das unidades de produção agrícola. Além disso, considerando que os dados são referentes à pesquisa de campo realizada apenas em um período, não foi possível realizar uma avaliação intertemporal, mais adequada para este tipo de estudo. 
Quadro 2 . Descrição e definição dos indicadores utilizados.

\begin{tabular}{|c|c|}
\hline Indicador & Descrição/ Definição \\
\hline AAA/UTH & $\begin{array}{l}\text { Avalia o grau de utilização da mão-de-obra em relação à área } \\
\text { efetivamente utilizada pelo agricultor para fins agrícolas e/ou } \\
\text { extrativistas. } \\
\text { AAA = Área de Ação Antrópica, em hectares. Compreende as } \\
\text { áreas utilizadas para o extrativismo e as áreas utilizadas com } \\
\text { fins agrícolas (SAU). } \\
\text { UTH = Unidade de Trabalho Homem. Corresponde a } 300 \text { dias de } \\
\text { trabalho, } 8 \text { horas/dia. } \\
\text { O indicador varia entre } 0 \text { e } 122,35 .^{*}\end{array}$ \\
\hline BAIX/SPT & $\begin{array}{l}\text { Avalia a importância da ocorrência de áreas planas ou com fra- } \\
\text { ca declividade em relação à área total da unidade de produção } \\
\text { agrícola. } \\
\text { BAIX = Área, em hectares, de baixadas na propriedade agrícola. } \\
\text { Corresponde às áreas sem declividade, planas, propícias ao cul- } \\
\text { tivo agrícola. } \\
\text { SPT = Superfície Própria Total, em hectares. Corresponde à área } \\
\text { total da propriedade agrícola do agricultor, medida em hectares. } \\
\mathrm{O} \text { indicador varia entre } 0 \text { e } 1 \text {. }\end{array}$ \\
\hline BENS & $\begin{array}{l}\text { Avalia a quantidade de bens e serviços que o produtor e sua } \\
\text { família têm acesso. Medido pela arbitragem de valores de acordo } \\
\text { com a situação encontrada, a soma dos valores dos parâmetros } \\
\text { fornece a informação a ser considerada (MOURA, 2002). } \\
\text { O somatório atinge valores entre, no mínimo, } 2 \text { e, no máximo, } \\
14 \text {. }\end{array}$ \\
\hline CRED & $\begin{array}{l}\text { Avalia a disponibilidade de acesso ao crédito agrícola, seja este } \\
\text { de custeio ou investimento, público ou privado. } \\
\text { Valores definidos por } 0 \text { quando não há acesso e } 1 \text { quando ocorre } \\
\text { acesso ao crédito. }\end{array}$ \\
\hline ESC & $\begin{array}{l}\text { Avalia o nível de escolaridade dos pais e dos filhos residentes na } \\
\text { propriedade. } \\
\text { Os anos de estudo dos pais são medidos considerando a maior } \\
\text { série estudada pelo pai ou mãe. Os anos de estudo dos filhos } \\
\text { foram medidos considerando a série estudada pelo filho que } \\
\text { mais estudou na família. Para o caso de uma pessoa estar estu- } \\
\text { dando, considerou-se o número de anos de estudos já realizados. } \\
\text { A soma dos valores dos parâmetros fornece a informação a ser } \\
\text { considerada (MOURA, 2002). } \\
\text { O somatório atinge valores entre, no mínimo, } 0 \text { e, no máximo, } \\
27 \text {. }\end{array}$ \\
\hline
\end{tabular}




\begin{tabular}{|c|c|}
\hline FLOR/SPT & $\begin{array}{l}\text { Avalia a ocorrência de áreas florestadas ou em regeneração nas } \\
\text { unidades de produção agrícolas. } \\
\text { FLOR = Área, em hectares, de floresta e capoeira na proprie- } \\
\text { dade agrícola, ou seja, áreas de preservação ou de baixa utiliza- } \\
\text { ção antrópica. } \\
\text { SPT = Superfície Própria Total do agricultor, medida em hect- } \\
\text { ares. Corresponde à área total da propriedade agrícola. } \\
\text { O indicador varia entre } 0 \text { e } 1 \text {. }\end{array}$ \\
\hline FUT & $\begin{array}{l}\text { Avalia a visão do futuro do agricultor em relação à situação so- } \\
\text { cioeconômica da família, possibilidade de permanência na ativi- } \\
\text { dade agrícola e participação futura dos filhos na propriedade. } \\
\text { Medido pela arbitragem de valores de acordo com a situação en- } \\
\text { contrada, sendo que a soma dos valores dos parâmetros fornece } \\
\text { a informação a ser considerada. } \\
\text { O somatório atinge valores entre, no mínimo, } 2 \text { e, no máximo, } 7 .\end{array}$ \\
\hline IDP & $\begin{array}{l}\text { Avalia o grau de diversificação de acesso ao mercado. } \\
\text { O Índice de Diversificação da Produção (IDP) corresponde ao } \\
\text { grau de dependência da unidade de produção agrícola em rela- } \\
\text { ção a cada produto comercializado. Calculado pela fórmula } \\
I D P=\frac{1}{\sum_{i=1}^{n}\left(F_{x}\right)^{2}} \\
\text { onde } F_{x} \text { é a fração do produto bruto total referente a cada } \\
\text { produto (HOFFMANN, 1984). } \\
\text { Considerando } 6 \text { tipos de atividade, o índice atinge valores entre, } \\
\text { no mínimo, } 1 \text { e, no máximo, } 6 \text {. }\end{array}$ \\
\hline IUS & $\begin{array}{l}\text { Avalia o grau de intensidade do uso agrícola do solo através da } \\
\text { avaliação do nível de utilização de insumos externos de origem } \\
\text { industrial na unidade de produção. } \\
\text { O Î́ndice de Uso do Solo (IUS) é calculado dividindo-se a quan- } \\
\text { tidade de insumos agrícolas e industriais, em quilos, pela Super- } \\
\text { fície Agrícola Útil (ha). } \\
\text { O nível alto corresponde a } 3,0 \text { (mais de } 300 \mathrm{~kg} / \mathrm{há} \text { ), nível médio } \\
\text { corresponde a } 2,0 \text { (entre } 50 \text { e } 300 \mathrm{~kg} / \mathrm{ha} \text { ) e nível baixo corre- } \\
\text { sponde a } 1,0 \text { (menos de } 50 \mathrm{~kg} / \mathrm{ha} \text { ). }\end{array}$ \\
\hline MNJ & $\begin{array}{l}\text { Avalia o modo de manejo empregado nas atividades relaciona- } \\
\text { das à produção da samambaia-preta. } \\
\text { Este indicador é medido pela arbitragem de valores de acordo } \\
\text { com o manejo utilizado. Os valores crescem de acordo com a } \\
\text { sustentabilidade do manejo em relação ao crescimento e à quali- } \\
\text { dade da folhagem, atingindo valores entre, no mínimo, } 1 \text { e, no } \\
\text { máximo, } 4 \text {. }\end{array}$ \\
\hline
\end{tabular}




\begin{tabular}{|c|c|}
\hline Nequip & $\begin{array}{l}\text { Avalia o nível de equipamento disponível nas unidades de } \\
\text { produção agrícolas. } \\
\text { Este indicador varia de } 1 \text { a } 4 \text {, sendo considerado } 1 \text { para o agri- } \\
\text { cultor com o maior nível de mecanização; } 2 \text { para o agricultor } \\
\text { semi-mecanizado; } 3 \text { para aquele que utiliza ferramentas manu- } \\
\text { ais e animais; e } 4 \text { para aquele que utiliza apenas ferramentas } \\
\text { manuais. }\end{array}$ \\
\hline NRS & $\begin{array}{l}\text { Avalia a renda total (em reais) proporcionada por cada unidade } \\
\text { de produção agrícola, ou seja, o nível de remuneração da mão- } \\
\text { de-obra familiar. } \\
\text { O Nível de Reprodução Social (NRS) é obtido pela renda total } \\
\text { (RT) dividida pela quantidade de mão de obra familiar emprega- } \\
\text { da na unidade de produção (UTHf). } \\
\text { Este indicador varia entre } 0 \text { e } 11.042,87 .^{*}\end{array}$ \\
\hline PART & $\begin{array}{l}\text { Avalia o grau de participação institucional da família, conside- } \\
\text { rando a participação em associações, em cooperativas, na comu- } \\
\text { nidade e em movimentos sociais ou políticos. } \\
\text { Medido pela arbitragem de valores de acordo com a situação en- } \\
\text { contrada, sendo que a soma dos valores dos parâmetros fornece } \\
\text { a informação a ser considerada. } \\
\text { O somatório atinge valores entre, no mínimo, } 0 \text { e, no máximo, } 4 \text {. }\end{array}$ \\
\hline RNA & $\begin{array}{l}\text { Avalia a importância e contribuição das rendas não-agrícolas na } \\
\text { constituição da renda total (RT) dos agricultores. Consideram-se } \\
\text { como rendas não-agrícolas a remuneração obtida pelos membros } \\
\text { da família fora da unidade de produção agrícola, como aposen- } \\
\text { tadoria, bolsa-escola, venda da força de trabalho de forma tem- } \\
\text { porária e/ou permanente e renda mobiliária e/ou fundiária. } \\
\text { Medido pela arbitragem de valores de acordo com a situação en- } \\
\text { contrada, sendo que a soma dos valores dos parâmetros fornece } \\
\text { a informação a ser considerada. } \\
\text { O somatório atinge valores entre, no mínimo, } 0 \text { e, no máximo, } 5 \text {. }\end{array}$ \\
\hline $\mathrm{SPT} / \mathrm{ST}$ & $\begin{array}{l}\text { Avalia a disponibilidade de áreas agrícolas próprias. Correspon- } \\
\text { de à participação das áreas agrícolas próprias em relação à to- } \\
\text { talidade das áreas agrícolas utilizadas na unidade de produção } \\
\text { agrícola. } \\
\text { SPT = Superfície Própria Total, em hectares. } \\
\text { ST = Superfície Total, medida em hectares. Corresponde à área } \\
\text { total da unidade de produção agrícola, somando áreas próprias, } \\
\text { ocupadas, arrendadas, emprestadas, etc. } \\
\text { Este indicador tem como valor máximo } 1 \text {, e como valor míni- } \\
\text { mo } 0 \text {. }\end{array}$ \\
\hline
\end{tabular}




\begin{tabular}{|c|c|}
\hline VA/AAA & $\begin{array}{l}\text { Proporciona uma avaliação da riqueza produzida nas áreas uti- } \\
\text { lizadas com atividades agrícolas e extrativistas. } \\
\text { VA = Valor Agregado, medido em reais. Corresponde à riqueza } \\
\text { líquida produzida no estabelecimento agrícola, ou seja, o valor } \\
\text { final dos produtos gerados no decorrer do ano no estabeleci- } \\
\text { mento agrícola (produção vendida, a produção consumida pela } \\
\text { família, a produção estocada, a produção utilizada na forma de } \\
\text { pagamento de serviços de terceiros e a variação do rebanho ani- } \\
\text { mal) descontado do valor dos insumos, do custo em manutenção } \\
\text { de instalações / equipamentos, serviços de terceiros utilizados no } \\
\text { decorrer de um ano agrícola assim como a depreciação dos equi- } \\
\text { pamentos e benfeitorias. } \\
\text { AAA = Área de Ação Antrópica, em hectares. } \\
\text { Este indicador varia entre } 0 \text { e } 2.196,54 \text {. }^{*}\end{array}$ \\
\hline VA/UTHf & $\begin{array}{l}\text { Proporciona a avaliação da riqueza produzida por cada unidade } \\
\text { de mão-de-obra familiar utilizada na unidade de produção agrí- } \\
\text { cola. } \\
\text { VA = Valor Agregado, medido em reais. } \\
\text { UTHf = Unidade de Trabalho Humano Familiar. } \\
\text { Este indicador varia entre } 0 \text { e } 9818,42 .^{*}\end{array}$ \\
\hline $\mathrm{VA} / \mathrm{KI}$ & $\begin{array}{l}\text { Avalia a capacidade que a unidade de produção agrícola possui } \\
\text { em gerar riqueza em relação ao capital investido em atividades } \\
\text { produtivas. } \\
\text { VA = Valor Agregado, medido em reais. } \\
\text { KI = Capital Imobilizado da unidade de produção agrícola, me- } \\
\text { dido em reais. Corresponde à soma dos valores de ativos como } \\
\text { terra, máquinas e equipamentos, ferramentas, etc. } \\
\text { O indicador apresenta como valor máximo } 0,75 \text { e como valor } \\
\text { mínimo } 0 \text {. }\end{array}$ \\
\hline 1-(CI/PBT) & $\begin{array}{l}\text { Avalia o grau de dependência da unidade de produção agrícola } \\
\text { para com insumos e serviços terceirizados externos, tanto em } \\
\text { nível da agricultura como do extrativismo. } \\
\text { CI = Consumo Intermediário, em reais. Compreende os gastos } \\
\text { com manutenção, insumos e serviços terceirizados. } \\
\text { PBT = Produto Bruto Total, em reais. Corresponde ao valor } \\
\text { final dos produtos gerados no decorrer do ano no estabeleci- } \\
\text { mento agrícola. Integra o Produto Bruto a produção vendida, } \\
\text { a produção consumida pela família, a produção estocada, a } \\
\text { produção utilizada na forma de pagamento de serviços de ter- } \\
\text { ceiros e a variação do rebanho animal. } \\
\text { Este indicador varia entre } 0 \text { e } 1 \text {. }\end{array}$ \\
\hline
\end{tabular}




\begin{tabular}{|c|l|}
\hline & $\begin{array}{l}\text { Avalia o nível de comprometimento da produção total da uni- } \\
\text { dade de produção agrícola com gastos gerais. } \\
\text { DT = Despesas Totais, em reais. Corresponde à totalidade das } \\
\text { 1-(DT/PBT) } \\
\text { despesas realizadas em uma unidade de produção agrícola no } \\
\text { decorrer de um ano agrícola. } \\
\text { PBT = Produto Bruto Total, em reais. } \\
\text { Este indicador varia entre 0 e 1. }\end{array}$ \\
\hline \multirow{3}{*}{ 1-(PBext/PBT) } & $\begin{array}{l}\text { Avalia a contribuição da atividade extrativista com samambaia-preta } \\
\text { na constituição da produção total da unidade de produção agrícola. } \\
\text { PBext = Produto Bruto do Extrativismo, em reais. Corresponde } \\
\text { à produça bruta oriunda da atividade extrativista, ou seja, da } \\
\text { venda de samambaia-preta. } \\
\text { PBT = Produto Bruto Total, em reais. } \\
\text { Este indicador varia entre 0 e 1. }\end{array}$ \\
\hline
\end{tabular}

Fonte: elaboração própria.

Nota: * valores máximos definidos a partir da metodologia especificada na seção 2.2 .

\subsection{Cálculo dos indicadores e índices}

Para a elaboração dos índices, primeiramente foram calculados, para cada observação, um indicador de cada critério (produtividade, estabilidade, equidade, resiliência, autonomia) em cada dimensão. Ou seja, 15 indicadores para cada observação, onde todos eles variam de 1, situação limite de insustentabilidade, a 2, situação de plena sustentabilidade. Os $j$-ésimos indicadores foram calculados para as $i$-ésimas observações numa fórmula de proporção entre 1 e 2 ,

$$
I_{j}=\frac{x_{j}-x_{\text {min }}}{x_{\text {máx }}-x_{\text {min }}}+1
$$

Os valores mínimos e máximos foram estimados de acordo com o formato do indicador. No caso de indicadores de "proporção", como SPT / ST, 1-(Pbext/PBT), BAIX / SPT, FLOR / SPT, SPT / ST, o valor mínimo foi dado como igual a zero e o valor máximo igual a um. Para indicadores de "valoração arbitrada", como NRS, RNA, CRED, IDP, MNJ, FUT, BENS, ESC, PART, os valores ficaram entre a soma mínima e a soma máxima que as observações poderiam atingir. Para os demais indicadores, considerando a amostra como representativa com distribuição normal, estimamos os valores máximos a partir da fórmula

$$
x_{\text {máx }}=z \cdot \hat{\sigma}+\overline{\mathrm{X}}
$$


onde $\hat{\sigma}$ e $\bar{X}$ são os respectivos estimadores da amostra para desvio-padrão e média da população, corrigidos para amostra infinita. Na estimação do valor máximo, consideramos $z=4$, ou seja, a probabilidade de algum elemento da população passar deste valor é ínfima, sendo menor que $0,00317 \%$. Já os valores mínimos foram limitados em

$$
\boldsymbol{x}=0 \text {, ou seja, } z=-\frac{\bar{X}}{\hat{\sigma}} .
$$

No caso de critérios compostos por dois indicadores, o indicador síntese do critério foi definido pela média aritmética dos dois anteriores.

Posteriormente foram calculados os Índices Relativos de cada Dimensão (IRD) e de cada Critério (IRC) para as observações, utilizando a média harmônica entre os indicadores. Ou seja, o IRD da $k$-ésima dimensão na $i$-ésima observação é

$$
I R D_{i k}=\left(\frac{1}{J} \sum_{k=1}^{J} I_{j}^{-1}\right)^{-1},
$$

onde $J$ é o número total de $j$ critério dentro de cada dimensão. Já o IRC do $k$-ésimo critério na $i$-ésima observação é

$$
I R C_{i k}=\left(\frac{1}{J} \sum_{k=1}^{J} I_{j}^{-1}\right)^{-1},
$$

onde $J$ é o número total de $j$ dimensões.

Para o Índice Relativo de Sustentabilidade (IRS) da observação, utilizando como foco tanto as dimensões (IRDs) quanto os critérios (IRCs), foi calculada a média harmônica dos índices anteriores. Ou seja, o IRS da $i$-ésima observação é

$$
I R S_{i}=\left(\frac{1}{J} \sum_{k=1}^{J} I R D_{k}^{-1}\right)^{-1},
$$

onde $J$ é o número total de $k$ dimensões, ou

$$
I R S_{i}=\left(\frac{1}{n} \sum_{k=1}^{n} I R C_{k}^{-1}\right)^{-1} \text {, }
$$

onde $J$ é o número total de $k$ critérios. 


\subsection{A tipologia dos Sistemas de Produção e a análise dos índices calculados}

Tipologia é a construção teórica baseada em um conjunto de hipóteses sobre a estrutura ou o comportamento de um sistema, levando em consideração a diversidade de seus elementos constituintes (e suas inter-relações). Na agronomia, é empregada para fundamentar a caracterização dos principais sistemas de produção colocados em prática pelos produtores rurais em determinado espaço geográfico. As tipologias de sistemas de produção são estruturadas na disponibilidade de fatores de produção, informações qualitativas e parâmetros de cunho socioeconômico, ambiental e agronômico (PGDR, 2002).

Pode-se definir um sistema de produção como a combinação, no tempo e no espaço, dos recursos disponíveis em um estabelecimento rural, com a finalidade de obter produções vegetais e animais. Além das atividades agropecuárias, a definição de sistema de produção abrange as atividades não-agrícolas realizadas nos estabelecimentos rurais (artesanato, venda da força de trabalho, etc.) (DUFUMIER, 1996).

De acordo com a metodologia proposta por Lima et al. (1995), o diagnóstico socioeconômico dos sistemas de produção implementados pelos agricultores envolvidos com a extração da samambaia levantou os seguintes aspectos e informações relativas às unidades de produção agrícolas: (a) identificação e inserção no meio físico e socioeconômico; (b) descrição e caracterização do meio natural; (c) estrutura produtiva; (d) funcionamento, dinâmica e organização do sistema de produção; (e) aspectos econômicos e financeiros; (f) resgate da trajetória evolutiva da unidade de produção. A partir das informações obtidas, foi elaborada uma tipologia dos principais sistemas de produção implementados pelos produtores da região em estudo. Essa tipologia levou em consideração a disponibilidade de fatores de produção e informações qualitativas de cunho socioeconômico e agronômico. Paralelamente, buscou-se repertoriar e descrever as diferentes formas de manejo da samambaia-preta implementadas.

Delimitaram-se os tipos de sistemas de produção implementados pelos agricultores da área de estudo, envolvidos com o extrativismo, separando as observações da amostra de acordo com o tipo de sistema na qual se insere cada uma. A partir desta distinção, a análise conteve- 
se na comparação dos IRDs, IRCs e IRSs entre os grupos de observações separadas por tipos. Verificando como os índices se comportam entre sistemas de produção distintos.

\section{Resultados}

Os primeiros levantamentos realizados nos três municípios abrangidos nesta pesquisa (Maquiné, Osório e Caraá) possibilitaram a identificação de 4 tipos de sistemas de produção implementados pelos agricultores envolvidos com o extrativismo da samambaia-preta. Estes sistemas de produção podem ser descritos como no Quadro 3.

Quadro 3. Definição dos tipos de Sistemas de Produção implementados pelos agricultores familiares "samambaieiros" do litoral norte do RS

\begin{tabular}{|c|l|}
\hline Tipo & \multicolumn{1}{c|}{ Descrição } \\
\hline $\mathbf{1}$ & $\begin{array}{l}\text { Pequenos agricultores familiares empobrecidos, geralmente localizados } \\
\text { nos fundos de vale (com maior dificuldade de acesso), dispondo de pro- } \\
\text { priedades agrícolas com áreas reduzidas e compostas em grande parte por } \\
\text { encostas; a prática da agricultura de autoconsumo pouco importante ou } \\
\text { ausente; tendo dependência total do extrativismo para geração de renda } \\
\text { no meio rural, com freqüente dependência do arrendamento de áreas de } \\
\text { terceiros para garantir sua quota anual de renda provinda do extrativismo; } \\
\text { além da extração da samambaia, estes agricultores, em alguns casos, ven- } \\
\text { dem a força de trabalho como diaristas ou empreiteiros. }\end{array}$ \\
\hline $\mathbf{2}$ & $\begin{array}{l}\text { Agricultores familiares empobrecidos, também localizados próximos aos } \\
\text { fundos de vale (a maioria), porém com áreas um pouco maiores, com al- } \\
\text { guma criação animal para autoconsumo e eventualmente comércio, além } \\
\text { de praticarem agricultura para autoconsumo; assim como o tipo anterior, } \\
\text { estes agricultores têm grande dependência do extrativismo para geração } \\
\text { de renda, e recorrem freqüentemente à venda da força de trabalho como } \\
\text { diaristas ou empreiteiros. }\end{array}$ \\
\hline $\mathbf{3}$ & $\begin{array}{l}\text { Agricultores familiares com atividade agrícola diversificada, com uma ou mais } \\
\text { entrada de capital via excedentes da produção de subsistência ou venda da } \\
\text { força de trabalho (diaristas ou empreiteiros na agricultura ou em atividades ur- } \\
\text { banas); a extração da samambaia têm função complementar à renda familiar. }\end{array}$ \\
\hline $\mathbf{4}$ & $\begin{array}{l}\text { Agricultores aposentados cujos filhos abandonaram a unidade de produção } \\
\text { agrícola; estes se dedicam apenas às atividades agrícolas, restringindo-as } \\
\text { às necessidades de autoconsumo ou pequenas criações; arrendam parte de } \\
\text { suas terras para compradores de samambaia-preta ou agricultores extrativis- } \\
\text { tas das proximidades; estes agricultores obtêm com o arrendamento e com } \\
\text { os benefícios de aposentadoria a maior parte da renda total. }\end{array}$ \\
\hline
\end{tabular}

Fonte: Elaboração própria a partir da pesquisa de campo, 2002. 
Na região, os sistemas de produção predominantes, entre os agricultores extrativistas, são representados pelos tipos 1 e 2 . $O$ tipo 3 aparece em número menos significativo que os dois primeiros, porém com certa freqüência. $\mathrm{O}$ tipo 4, por não realizarem diretamente a extração da samambaia-preta, não foi abordado neste estudo. Assim, somente os três primeiros foram considerados na mensuração da sustentabilidade, por se envolverem diretamente com o extrativismo.

De um modo em geral, a forma implementada pela maioria dos agricultores no manejo e na organização do espaço agrícola caracteriza-se por uma intervenção antrópica superficial e limitada à prática de coleta da fronde. Este manejo ocorre através da prática de desbaste esporádico de parte da vegetação arbustiva e arbórea. Identificaram-se ainda, porém em pequeno número, agricultores que implementam modos distintos de manejo, estes são caracterizados pelas intervenções e práticas agrícolas ordenadas e de caráter contínuo, implementando um sistema de cultivo de queimada com culturas anuais (em grande parte com as culturas do milho e do feijão) seguidas por um período de pousio com duração superior a três anos.

Dentre os tipos de sistemas de produção pesquisados constataramse algumas diferenças nos IRD e IRC apresentados por cada tipo considerado. Os resultados dos índices estão expressos na Tabela 1.

Tabela 1. Índices Relativos de Sustentabilidade por tipos de agricultores extrativistas do litoral do RS

\begin{tabular}{|c|c|c|c|c|c|c|c|c|c|}
\hline \multirow{2}{*}{ Tipos } & \multicolumn{3}{|c|}{ DIMENSÃO } & \multirow{2}{*}{\multicolumn{5}{|c|}{$\begin{array}{c}\text { CRITÉRIO } \\
\end{array}$}} & \multirow{2}{*}{ IRS } \\
\hline & Econ & $\mathrm{Amb}$ & Soc & & & & & & \\
\hline $\begin{array}{c}\mathbf{1} \\
\text { (Pequeno } \\
\text { agricultor familiar } \\
\text { extrativista) }\end{array}$ & 1,30 & 1,42 & 1,37 & 1,19 & 1,33 & 1,45 & 1,34 & 1,55 & 1,36 \\
\hline $\begin{array}{c}\mathbf{2} \\
\text { (Agricultor } \\
\text { familiar } \\
\text { extrativista com } \\
\text { agricultura de } \\
\text { subsistência) } \\
\end{array}$ & 1,31 & 1,37 & 1,43 & 1,14 & 1,38 & 1,39 & 1,42 & 1,58 & 1,37 \\
\hline $\begin{array}{c}\mathbf{3} \\
\text { (Agricultor } \\
\text { familiar } \\
\text { extrativista com } \\
\text { atividades } \\
\text { não-agrícolas) }\end{array}$ & 1,42 & 1,41 & 1,55 & 1,26 & 1,48 & 1,49 & 1,43 & 1,71 & 1,46 \\
\hline
\end{tabular}

Fonte: Elaboração própria a partir da pesquisa de campo, 2003. 
Colocando em ordem de sustentabilidade os sistemas de produção, verifica-se que o sistema de produção do tipo 3 se mostrou o mais sustentável. Os tipos 1 e 2, por composições distintas, apresentam IRSs semelhantes, estando mais próximos do que se poderia chamar de uma situação "insustentável”. A Tabela A1, em anexo, apresenta resultados mais detalhados.

Através da Tabela 1, pode-se perceber que na constituição do IRS, dos três tipos, o critério de autonomia tem o maior valor, enquanto o critério de produtividade possui o menor. Ou seja, os três sistemas apresentam um elevado grau de autonomia, mas baixa produtividade. Isso reflete a situação da agricultura na região: uma agricultura pouco dinâmica e fortemente influenciada por limitações de ordem legal e ambiental.

Apesar do tipo 3 apresentar os maiores valores, é possível perceber que, em decorrência da metodologia proposta, ele está muito aquém de um ideal sustentável, assim como os outros tipos. Ou seja, considerando a amostra como representativa da região, constata-se que os agricultores "samambaieiros" locais apresentam certa vulnerabilidade em seus sistemas, principalmente nas dimensões econômica e ambiental e nos critérios de produtividade, estabilidade e resiliência.

Na comparação entre os sistemas de produção em relação às dimensões, o Gráfico 1 evidencia as diferenças.

Gráfico 1. Índices Relativos por dimensão dos tipos de sistemas de produção identificados entre os agricultores extrativistas do litoral do RS

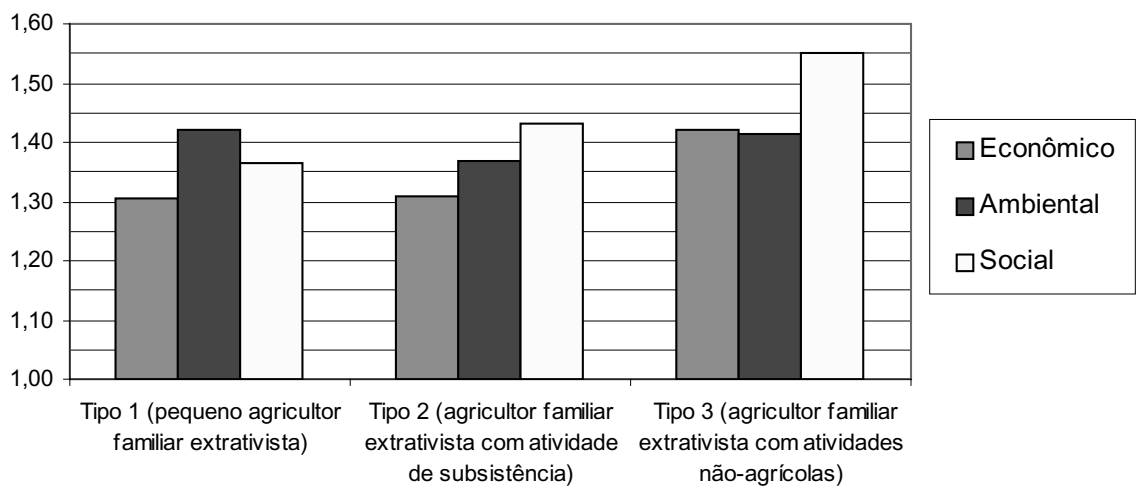

Fonte: Elaboração própria a partir da pesquisa de campo, 2003. 
Como observado, o tipo 3 apresenta as dimensões econômica e social superiores aos dos demais tipos, entretanto seu índice ambiental é praticamente igual ao tipo 1. Economicamente, o tipo 3 é superior aos demais por ter os critérios de estabilidade, equidade e autonomia elevados. Isso decorre do fato que o sistema dele apresenta uma menor dependência do extrativismo, um maior nível de reprodução social e um maior volume de produção ao longo do ano. Além disso, na dimensão social, o destaque do tipo 3 deve-se a sua superioridade principalmente em produtividade e equidade nessa dimensão.

Na distribuição das variáveis correspondentes a cada critério, o Gráfico 2 evidencia o comportamento nos diferentes sistemas de produção identificados. O critério produtividade é relativamente inferior em todos tipos. A principal causa para esta situação é a baixa produtividade da superfície agrícola útil na geração do produto vegetal e animal. Fator esse justificado pela situação sócio-econômica-ambiental predominante na região, a qual impõe necessárias restrições à atividade agropecuária.

Gráfico 2. Índices Relativos por critérios dos tipos de sistemas de produção identificados entre os agricultores extrativistas do litoral do RS

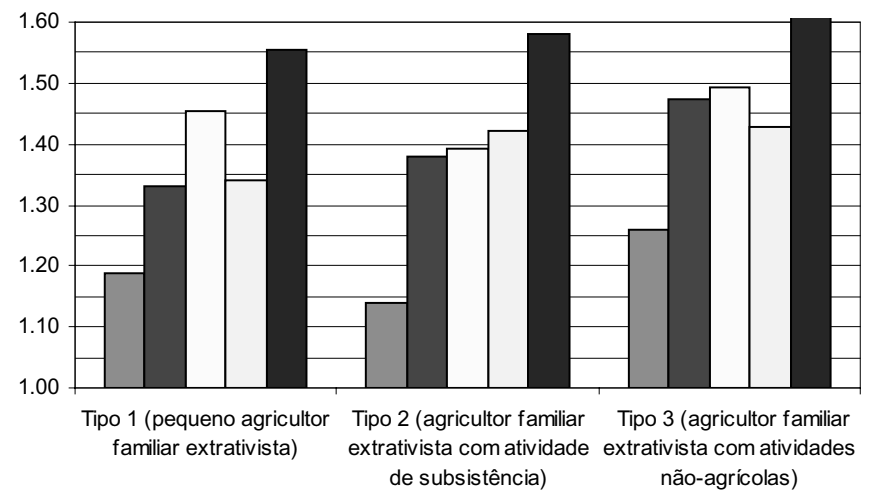

$\square$ Produtividade

$\square$ Estabilidade

$\square$ Equidade

$\square$ Resiliência

$\square$ Autonomia

Fonte: Elaboração própria a partir da pesquisa de campo, 2003.

A autonomia tem destaque nos três sistemas, principalmente no tipo 3 , apresentando valores significativamente elevados. Isso se deve à autonomia econômica ser bastante elevada nos três tipos, refletindo a relação entre despesas e produto bruto. Ou seja, os três tipos de agricultores possuem sistemas de produção que apresentam baixas despesas em relação 
à produção gerada. No critério de estabilidade, o destaque do tipo 3 também é explicado pela dimensão econômica. Ele possui um maior valor de produto gerado ao longo do ano, além de uma maior diversificação da produção e de acesso a mercados, muito baixos nos demais tipos.

No critério de resiliência, apesar dos três tipos estarem com baixos valores, nota-se a relativa inferioridade do tipo 1. A principal razão para essa inferioridade nos valores de resiliência está na dimensão econômica. De fato, em termos de resiliência econômica, a grande maioria dos agricultores que compõem o tipo 1 não tem acesso ao crédito de nenhuma forma.

Por fim, a avaliação do conjunto de resultados aponta uma preponderância dos indicadores da dimensão econômica na constituição do IRS, segundo cada critério. Os indicadores sociais apresentam uma importância secundária na diferenciação dos sistemas. Enquanto os indicadores ambientais apresentam uma fraca influência na composição do IRS, pois é onde os produtores pouco se diferenciam. Entre os critérios, a situação é mais diversa, sendo que o fator que pouco diferencia os sistemas de produção, segundo cada dimensão, é a resiliência.

\section{Considerações Finais}

A partir dos critérios delimitados neste estudo, os resultados preliminares apontaram para a existência de três sistemas de produção implementados pelos agricultores familiares envolvidos com o extrativismo da samambaia-preta na região da Encosta Atlântica do RS. Os sistemas de produção predominantes entre os agricultores extrativistas locais foram representados pelos tipos 1 e 2. Esses sistemas se caracterizam pela baixa disponibilidade de meios de produção e por uma grande dependência de rendas não-agrícolas, como aposentadoria, venda da força de trabalho para outros estabelecimentos agropecuários ("diaristas", "empreiteiros”), além do extrativismo. O sistema de produção do tipo 3 é caracterizado pela disponibilidade de meios de produção de maior relevância, como terras, equipamentos e animais de criação, e por desenvolver, além da agricultura de subsistência, atividades agrícolas de cunho comercial. Nesse sistema de produção, a coleta de folhagem é uma fonte de renda unicamente complementar, havendo ainda 
a ocorrência de terceirização das atividades extrativistas, através do arrendamento de áreas para outros agricultores locais.

Com referência ao manejo e organização do espaço agrícola relacionado ao extrativismo da folhagem, a forma implementada pela maioria dos agricultores da região se caracteriza por uma intervenção antrópica superficial e limitada à prática de coleta da fronde. Esse manejo está fundamentado na realização de prática de desbaste esporádico de parte da vegetação arbustiva e arbórea. Em contrapartida, pode-se identificar um pequeno número que implementa formas distintas de manejo, caracterizadas pelas intervenções e práticas agrícolas ordenadas e de caráter contínuo. Essas formas são implementadas em áreas submetidas ao sistema de cultivo de queimada com culturas anuais (milho/feijão) e com pousio de 10 anos de duração.

Na maior parte dos casos, constatou-se que os “samambaieiros” são agricultores familiares fragilizados econômica, social e ambientalmente, que dispõem de superfícies agrícolas reduzidas, em grande parte localizadas em áreas de encosta ou de difícil acesso.

Considerando a definição de sustentabilidade como o uso dos recursos biofísicos, econômicos e sociais, segundo sua capacidade em um espaço geográfico, para obter bens e serviços da agricultura e dos recursos naturais para satisfazer as necessidades das gerações, foram considerados cinco critérios (produtividade, estabilidade, equidade, resiliência e autonomia), em três dimensões (econômica, ambiental e social), nas medidas para a avaliação dos sistemas de produção. Os agricultores que implementam o sistema de produção do tipo 3 apresentaram algum destaque entre os demais, principalmente pela dimensão econômica. Do outro lado, os agricultores no sistema de produção do tipo 1 apresentaram os piores índices de sustentabilidade. Por conseguinte, eles expuseram a elevada fragilidade sócio-econômica-ambiental dos agricultores familiares que implementam este sistema de produção no Litoral Norte do Rio Grande do Sul.

\section{Referências Bibliográficas}

\section{ANAMA; PGDR-UFRGS; RS-RURAL. Avaliação etnobiológica e socio- econômica da samambaia-preta (Rumohra adiantiformis (G.Forest.)}


Ching) na região da Encosta Atlântica do Estado. Porto Alegre, junho de 2003, 111p. (Relatório de Pesquisa, Pesquisa por Demanda - RS RURAL, Secret. Agricultura e Abastecimento, RS).

CONSÓRCIO MATA ATLÂNTICA; UNICAMP. Reserva da Biosfera da Mata Atlântica. Plano de ação v.1: Referências básicas, São Paulo, 1992.

DUFUMIER, M. Les projets de développement agricole. Paris: KARTHALA - CTA, 1996, 354p.

EHLERS, E. M. Agricultura Sustentável: origens e perspectivas de um novo paradigma. São Paulo: Livros da Terra, 1996. 178p.

FERREIRA, J. R. C. Evolução e Diferenciação dos Sistemas Agrários do Município de Camaquã-RS: uma análise da agricultura e suas perspectivas de desenvolvimento. Porto Alegre: UFRGS, 2001. 192p. (Dissertação de Mestrado em Economia Rural)

GERHARDT, C. H. et al. Diagnóstico socioeconômico e ambiental do município de Maquiné - RS: perspectivas para um desenvolvimento rural sustentável. Relatório de Pesquisa, ANAMA - PGDR/ UFRGS - Prefeitura Municipal de Maquiné, Porto Alegre, 2000. 56p.

HOFFMANN, R. et al. Administração da Empresa Agrícola. São Paulo: Pioneira, 1984. 325p.

KLEIN, R. M. Southern Brazilian phytogeographic features and the probable influence of upper quaternary climatic changes in the floristic distribution. Boletim Paranaense Geociências, n. 33, 1975. p. 67-88.

LIMA, A. P. et al. Administração da unidade de produção familiar. Ijuí : UNIJUÍ, 1995, 175p.

LOPES, S. B. Arranjos Institucionais e a Sustentabilidade de Sistemas Agroflorestais: uma posição metodológica. Porto Alegre: UFRGS, 2001. 173p. (Dissertação de Mestrado em Desenvolvimento Rural)

MOURA, L. G. V. Indicadores para avaliação da sustentabilidade em sistemas de produção da agricultura familiar: o caso dos fumicultores de Agudo/RS. Porto Alegre: PGDR/UFRGS, 2002. 251 p. (Dissertação, Mestrado em Desenvolvimento Rural). 
PGDR, Glossário Evolutivo Comum. In: Evolução e diferenciação da agricultura, transformação do meio natural e desenvolvimento sustentável em municípios da Planície Costeira e Planalto Sul-rio-grandense: uma abordagem interdisciplinar (Relatório de Pesquisa). Porto Alegre: UFRGS, 2002. mimeo

RIBAS, R. P. et al. Aspectos econômicos e sociais da Cadeia Produtiva da Samambaia-preta (Rumohra adiantiformis (G. Forest.) Ching) na região da Encosta Atlântica do Estado do RS. Redes, Santa Cruz do Sul: UNISC, v. 7, n. 2, p. 153-166, maio/ago. 2002

RIBAS, R. P.; MIGUEL, L. A. Extração e comercialização de folhagens ornamentais da Mata Atlântica: o caso da verdes (Rumohra adiantiformis) no RS. Revista de Economia e Sociologia Rural, v. 42, n. 4, p. 575-596, 2003.

Recebido em agosto de 2005 e revisto agosto de 2006. 


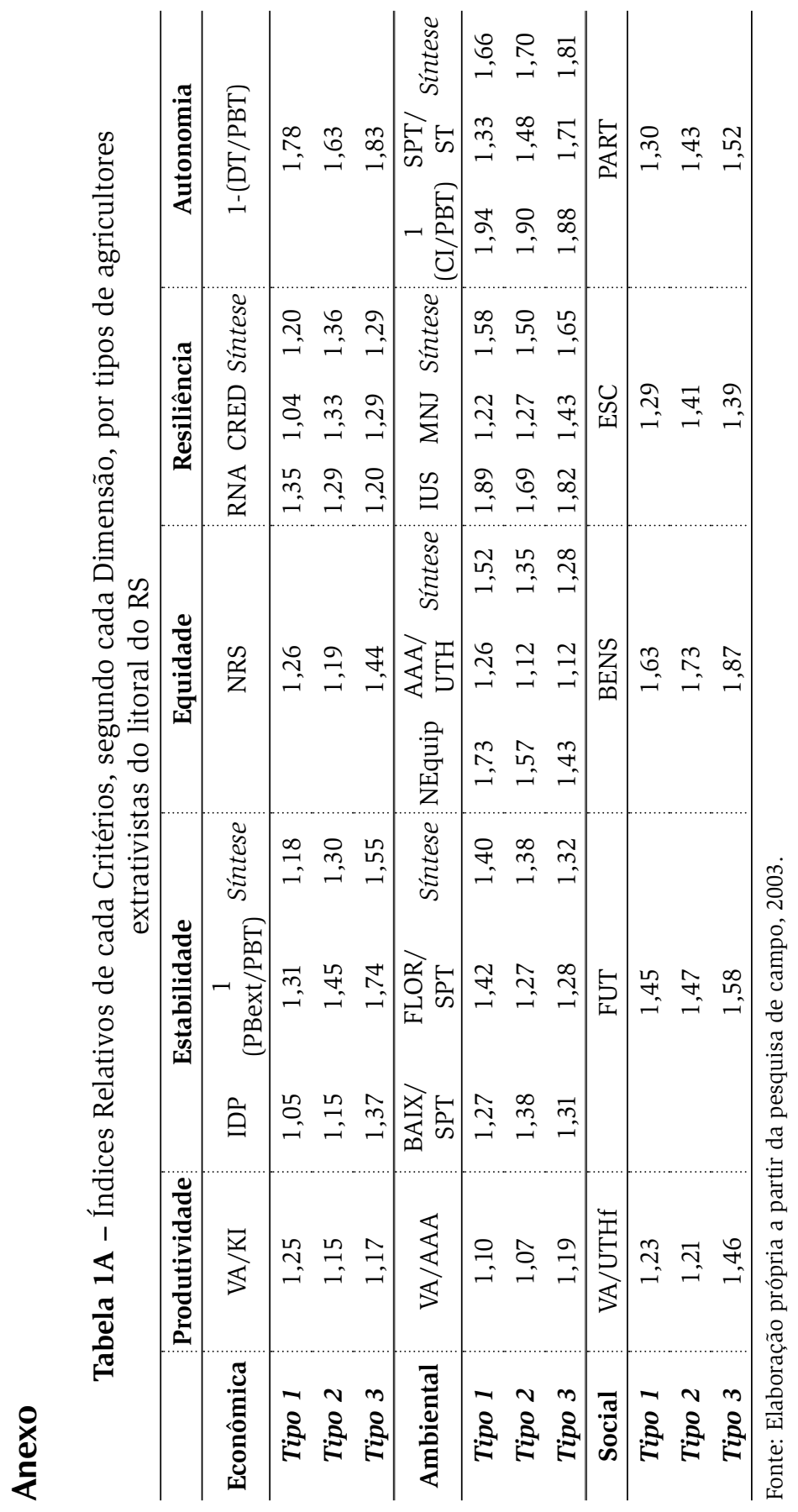

